\title{
The size of aurochs skeletons from Europe and Asia in the period from the Neolithic to the Middle Ages
}

\author{
Alicja LASOTA-MOSKALEWSKA and Henryk KOBRYŃ
}

\begin{abstract}
Lasota-Moskalewska A. and Kobryń H. 1990. The size of aurochs skeletons from Europe and Asia in the period from the Neolithic to the Middle Ages. Acta theriol. 35: 89-109.

Statistical analysis was carried out of 1838 dimensions of 25 osteometric characteristics of the aurochs Bos primigenius Bojanus, 1827 skeleton in order to determine the secular trend and geographic gradient. The results showed a slight tendency for an increase in the dimensions of the forelimbs with the passage of time. Both limbs showed no change in size of the stylopodium, zeugopodium or metapodium; the acropodium increased in size. The size of skeletons was found to decrease from East to West. This applied to both pairs of limbs, but in the case of the forelimbs the gradient was steeper. It did not occur in the stylopodium or zeugopodium, but could be detected in the metapodium and acropodium. This was the case only with females (analysis based on 7 characteristics).

Institute of Archeology of Warsaw University, Widok 10, 00-023 Warsaw, Poland (AL-M); Department of Animal Anatomy, Warsaw Agricultural University, Nowoursynowska 166, 02-766 Warsaw, Poland (HK)

Key words: skeleton size, Bos primigenius, secular trend, geographic gradient
\end{abstract}

\section{Introduction}

Many authors have described the differentiation in size of aurochs Bos primigenius Bojanus, 1827 skeletons. Variation has been noted on both a chronological and geographical scale, although there are still many debatable questions. It would, however, seem indisputable that the Pleistocene aurochs was larger than the Holocene (Requate 1957, Jewell 1962, Degerbøl and Fredskild 1970, Vörös 1987).

On the basis of descriptions of changes that occurred in other species of mammals, consisting in a diminution of their size in the post-glacial period, it is feasible to expect that the aurochs exhibited similar tendencies, and that its dimensions also decreased. Tendencies of this kind have been indicated in the case of carnivore by Kurtén (1965), in the case of American bison by McDonald (1981), for the wild boar in Western Europe by Jonsson (1986), and for deer by Mystkowska (1966), Morales (1979), Vörös (1979) and Wyrost and Chrzanowska (1985).

Geographic variation has similarly been described for several species of mammals: for deer (Beninde 1937, Mystkowska 1966, Morales 1979, Noddle 1982) and for wild boar (Jonsson 1986, Lasota-Moskalewska et al. 1987).

Both types of changes have been investigated in the case of the aurochs in the Holocene period by Jewell (1962), Grigson (1969), Jarman (1969), Calkin (1970), Degerbøl and Fredskild (1970), Ekmann (1972), Driesch and Boessneck (1976) and 
Vörös $(1980,1985)$. The tendencies described were, however, often contradictory. A review article giving an overview of the discussion on the subject was published by Muzzolini (1985). But it is also difficult on the basis of this article to form a firm and conclusive judgment on whether a secular trend and gradient of geographical changes can be detected for the aurochs skeleton in the Holocene period. Examinations of these changes were often based on comparisons of small quantities of materials: on data from individual sites, countries or regions. Moreover, only a small number of osteometric characteristics was used, taking into account those fragments of bones which are more frequently preserved in excavated materials. The differences (or absence of difference) described could therefore have been an effect of phenotypical differentiation resulting from local ecological conditions, or the position of a given bone in the skeleton.

We used many osteometric data collected in the literature, and also that from our own archaeological research, which forms a data base larger than any hitherto published. We have undertaken on the basis of this material an attempt to discover whether the aurochs skeleton in the Holocene period was subject to a secular trend, and also whether it exhibited tendencies to variations linked with the geographical zone in which it occurred.

Table 1. Osteometric characteristics of aurochs used in this work.

\begin{tabular}{|c|c|c|c|c|}
\hline \multirow{2}{*}{ Characteristic } & \multirow{2}{*}{ Symbol } & \multicolumn{3}{|c|}{ Number of measurements } \\
\hline & & 30 & 우우 & Total \\
\hline Processus cornualis - basal circumference & $\mathrm{HBC}$ & 44 & 66 & 110 \\
\hline Scapula - length of collum & SLC & 19 & 75 & 94 \\
\hline Humerus - breadth of distal end & HBD & - & - & 96 \\
\hline Radius - breadth of proximal end & RBP & 21 & 46 & 67 \\
\hline Radius - breadth of distal end & RBD & - & - & 51 \\
\hline Metacarpus - greatest length & McGL & - & - & 28 \\
\hline Metacarpus - breadth of proximal end & McBP & 19 & 89 & 108 \\
\hline Metacarpus - breadth of diaphysis & MCSD & - & - & 34 \\
\hline Metacarpus - breadth of distal end & McBD & 34 & 87 & 121 \\
\hline Tibia - breadth of proximal end & TBP & - & - & 10 \\
\hline Tibia - breadth of distal end & TBD & 48 & 94 & 142 \\
\hline Calcaneus - greatest length & CGL & 14 & 46 & 60 \\
\hline Talus - lateral length & AGLl & - & - & 92 \\
\hline Talus - breadth of distal end & $\mathrm{ABD}$ & - & - & 82 \\
\hline Metatarsus - greatest length & MtGL & - & - & 24 \\
\hline Metatarsus - breadth of proximal end & MtBP & - & - & 56 \\
\hline Metatarsus - breadth of diaphysis & MtSD & - & - & 23 \\
\hline Metatarsus - breadth of distal end & $\mathrm{MtBD}$ & - & - & 59 \\
\hline Phalanx $I$-greatest length & PhIGL & - & - & 124 \\
\hline Phalanx $I$ - breadth of proximal end & PhIBP & - & - & 124 \\
\hline Phalanx $I$ - breadth of distal end & PhIBD & - & - & 97 \\
\hline Phalanx II - greatest length & PhIIGL & - & - & 79 \\
\hline Phalanx II - breadth of proximal end & PhIIBP & - & & 69 \\
\hline Phalanx II - breadth of distal end & PhIIBD & - & - & 69 \\
\hline \multirow[t]{2}{*}{ Phalanx III - length of the sole } & PhIIIDLS & - & & 19 \\
\hline & Total & 199 & 503 & 1838 \\
\hline
\end{tabular}




\section{Material}

The osteometric data on the aurochs skeleton used in this study have been analysed previously in two other studies dealing with aurochs and domestic cattle (Kobryń and Lasota-Moskalewska 1989, Lasota-Moskalewska and Kobryń 1989). Measurements taken from Vörös's study (1987) have been added to this material. The osteometric material deals with 25 morphological characteristics (Table 1). In all, we had at our disposal 1838 bone dimensions (or more frequently dimensions of measurable bone fragments) of aurochs living in Europe and Asia between about $6000 \mathrm{BC}$ and $1500 \mathrm{AD}$.

\section{Methods}

The secular trend in aurochs skeleton dimensions and their geographical differentiation was examined. In order to investigate the secular trend, osteometric material was selected from the territory of Poland, Czechoslovakia, East Germany, West Germany, Belgium and Switzerland: that is, from countries where the aurochs survived longest. These data were from the period from c. $5500 \mathrm{BC}$ to $\mathrm{c}$. $1500 \mathrm{AD}$. This material was divided into two chronological groups, in order to obtain a maximum quantity of data in each. The first group (period A) fell within the period from c. $5500 \mathrm{BC}$ to c. $1500 \mathrm{BC}$, and basically covered the whole Neolithic age. The second group (period B) fell between c. $1500 \mathrm{BC}$ and $1500 \mathrm{AD}$ and covered the whole Bronze Age and Iron Age up to the middle ages. In both time groups the arithmetic mean $(\overline{\mathrm{x}})$ and standard deviation (SD) were calculated for the dimensions of each characteristic. For 7 characteristics, this was calculated separately for each sex. For this purpose only those characteristics were used in which the distribution of dimensions made it possible to differentiate between the bones of males and females (Kobryń and Lasota-Moskalewska 1989).

In order to be able to cross-compare individual characteristics, a point scale was constructed for 25 osteometric characteristics, making use of data from all chronological periods and geographical regions (Fig.1). This scale was worked out according to the principles described by Lasota-Moskalewska (1980). In view of the necessity of accommodating the span of the dimensions (minimum-maximum) to a 100 point scale, in several cases it was necessary to reject the extrema dimensions which did not fit into a coherent distribution frequency. It was possible to conclude that these represented individuals which were atypical within the population, or were perhaps the result of errors in identifying or measuring the bones. Next, every dimension was transposed into points, thus obtaining an abstract value which was comparable irrespective of the type and size of the characteristic. The range of points from 0 to 100 was divided, using conventional criteria, into three categories: (1) a small dimension - from 0 to 29 points; (2) a medium dimension - from 30 to 69 points; (3) a large dimension - from 70 to 100 points. In the case of examination of the variability of dimensions separately for males and females, the point scale was divided into only two categories: (1) a small dimension males: $40-69$ points, females $0-29$ points; (2) a large dimension males: $70-100$ points, females $30-60$ points. The points limits for large females and small males often overlap. This is because each characteristic had a different size distribution in the two sexes. When transposed into points, some characteristics of females spanned over as many as 60 points, while other characteristics in males had a span of barely 40 points. The division of dimensions by sex was arrived at in line with findings based on an empirical distribution of dimensions and not the number of points (Kobryń and Lasota-Moskalewska 1989). Dimensions which could not be attributed to a particular sex were discounted.

The dimensions, once points had been accorded and they had been grouped according to the above scheme, were compared in two chronological groups (periods A and B). For this purpose, the random correlation method was used. The significance of differences between empirical and theoretically predictable distribution was investigated using the $\gamma^{2}$ test, as follows:

$$
\chi^{2}=\Sigma \frac{(n-\hat{n})^{2}}{n}, \text { when } v=(k-1) \times(r-1),
$$

where: $n$-actual size: $n$-theoretically predictable size, $v$-degree of freedom, $k$-number of columns. $r$-number of rows. 

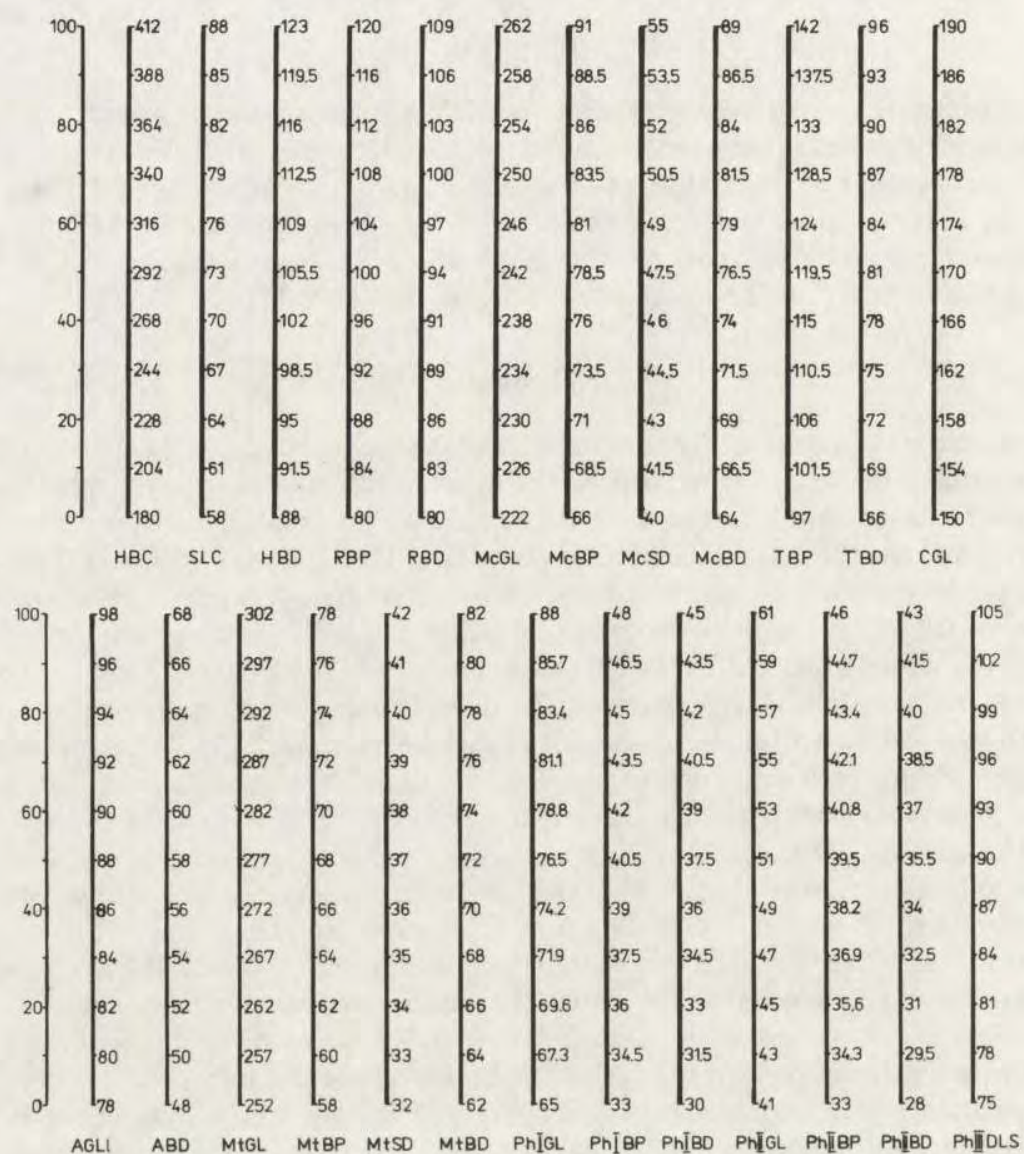

Fig. 1. Points $\left(\begin{array}{ll}0 & 100\end{array}\right)$ and the corresponding absolute values of aurochs bone dimensions ( $m m$ ). Sy mbols of dimensions given in Table 1.

The significance of surpluses or deficiencies in particular bones in the table was tested with the $\Psi$ test (Góralski 1966), as follows:

$$
\Psi=\frac{n-\hat{n}}{\delta_{(\hat{p})} \sqrt{n(1-\hat{p})}}
$$

where: $\delta_{(\dot{p})}$ value read from the appropriate table in the study cited, resulting from the probability of occurrence of a dimension defined by a given category, and the probability of occurrence of the dimension in a given period (A or B) or in another grouping, for example a geographical group $(\mathrm{P}, \mathrm{E}, \mathrm{W}, \mathrm{S}) ; \hat{p}=\frac{\hat{n}}{N}$, where: $N$ - the number of data in the whole table.

The difference in the participation of bones of males and females in particular periods (or geographical groups) was tested by the appropriate form of the $\chi^{2}$ test, as follows:

$$
\chi^{2}=\frac{\left[n_{1}-\frac{1}{2}\left(n_{1}+n_{2}\right)\right]^{2}}{\frac{1}{2}\left(n_{1}+n_{2}\right)}+\frac{\left[n_{2}-\frac{1}{2}\left(n_{1}+n_{2}\right)\right]^{2}}{\frac{1}{2}\left(n_{1}+n_{2}\right)} \text {, when } v=1
$$


where: $n_{1}-$ number of females, $n_{2}-$ number of males.

To examine the variability of the dimensions of forelimbs, the following characteristics were used: HBD, RBP, RBD, McGL, McBP, McSD, McBD. For the hind limbs the following characteristics were examined: TBP, TBD, CGL, AGLI, ABD, MtGL, MtBP, MtSD, MtBD. The variability of the stylopodium was examined on the basis of only one characteristic: HBD, since we did not have at our disposal dimensions of the thigh bone. The variability of the zeugopodium was examined on the basis of the following characteristics: RBP, RBD, TBP, TBD. The metapodium covered the following characteristics: McGL, McBP, McSD, McBD, MtGL, MtBP, MtSD, MtBD. The acropodium covered: PhIGL, PhIBP, PhIBD, PhIIGL, PhIIBP, PhIIBD, PhIIIDLS.

To examine the second problem - geographical variation in the dimension of aurochs skeletons - the whole osteometric material was used. It was divided into geographical groups according to conventional criteria. Poland $(\mathrm{P})$, because it was here that the aurochs occurred over the longest period, was treated as the central territory and the point of reference for other regions. Territory lying to the East of Poland (E) covered the Soviet Union and Iraq. The territory to the West of Poland (W) covered Germany and Belgium. The territory to the South of Poland (S) covered Czechoslovakia, Hungary, Roumania, Yugoslavia and Switzerland. The territory to the North of Poland (N) covered Sweden. In this last case, we had at our disposal only a dozen or so dimensions of one female aurochs (Ekmann 1972). For this reason, the North was not taken into consideration in comparative statistical analyses.

To trace geographical variability in the size of aurochs skeletons the same methods were applied as in analysis of the secular trend. However, the materials used to analyse this variability were wider both territorially and chronologically.

\section{Results}

Changes in the size of the aurochs skeleton with the passage of time (secular trend).

To examine the changes occurring in the aurochs skeleton over roughly 7,000 years, 877 bone dimensions from period A were analysed: from c. 5500 to c. $1500 \mathrm{BC}$, and 414 dimensions from period B, from c. $1500 \mathrm{BC}$ to $1500 \mathrm{AD}$. These dimensions applied to all 25 osteometric characteristics examined. Preliminary comparisons consisted in defining the direction of change of the arithmetic mean, calculated for each period. The value of some characteristics decreased with the passage of time, while others increased, and there were also some which exhibited a contrary direction of change for males and females (Table 2). The size of these changes was very small, and this, given the fairly wide range of variability (from minimum to maximum) and what was often a limited number of cases, suggested that they were random. There was therefore a second stage of analysis, which offered the possibility of common evaluation of all the characteristics or groups of characteristics, based on the position of the bones in the skeleton.

For this purpose the dimensions were directly transposed into points, using the point scale. The distribution frequencies of points obtained for all characteristics exhibit skewness, with a clustering of points in the categories of small values (Table 3 ). It seems that this clustering is greater in period A than period B. It is therefore possible to suggest that the skeleton of aurochs living in the earlier period had somewhat larger dimensions. To check whether this suggestion was real rather than apparent, 
Table 2. Dimensions of aurochs skeleton in periods A and B ( $\mathrm{mm})$.

\begin{tabular}{|c|c|c|c|c|c|c|c|c|c|c|c|}
\hline \multirow[t]{2}{*}{ Symbol } & \multirow[t]{2}{*}{ Sex } & \multicolumn{5}{|c|}{ A } & \multicolumn{5}{|c|}{ B } \\
\hline & & $\mathrm{n}$ & $\min$ & $\max$ & $\bar{x}$ & SD & $\mathrm{n}$ & $\min$ & $\max$ & $\bar{x}$ & SD \\
\hline \multirow{2}{*}{ НBC } & & 26 & 275 & 392 & 340.5 & 30.9 & 4 & 286 & 350 & 330.8 & 30.4 \\
\hline & & 39 & 179 & 273 & 227.9 & 26.7 & 8 & 200 & 245 & 223.6 & 17.8 \\
\hline \multirow{2}{*}{ SLC } & 17 & 10 & 75 & 86 & 80.2 & 3.8 & 3 & 76 & 84 & 79.3 & 4.2 \\
\hline & 우우 & 34 & 58 & 74 & 64.0 & 5.1 & 5 & 59 & 70 & 62.2 & 4.4 \\
\hline HBD & & 50 & 98 & 120 & 102.2 & 8.8 & 16 & 92 & 124 & 104.6 & 11.4 \\
\hline \multirow[t]{2}{*}{ RPB } & & 10 & 110 & 122 & 115.2 & 4.1 & 4 & 115 & 118 & 116.0 & 1.4 \\
\hline & & 21 & 90 & 104 & 99.6 & 4.5 & 6 & 90 & 101 & 95.8 & 4.7 \\
\hline \multirow{2}{*}{$\begin{array}{l}\text { RBD } \\
\text { McGL }\end{array}$} & & 31 & 80 & 104 & 93.5 & 8.7 & 8 & 81 & 110 & 96.4 & 11.1 \\
\hline & & 12 & 230 & 259 & 246.4 & 9.0 & 6 & 235 & 247 & 241.0 & 4.3 \\
\hline \multirow{2}{*}{ McBP } & & 6 & 80 & 88 & 84.0 & 2.8 & 7 & 81 & 88 & 83.6 & 2.6 \\
\hline & & 53 & 66 & 79 & 71.9 & 3.4 & 6 & 67 & 77 & 71.3 & 3.9 \\
\hline McSD & & 17 & 42 & 53 & 47.2 & 3.9 & 6 & 42 & 56 & 49.3 & 6.0 \\
\hline \multirow[t]{2}{*}{ McBD } & & 11 & 80 & 88 & 83.8 & 2.7 & 9 & 80 & 87 & 83.7 & 2.5 \\
\hline & & 47 & 64 & 79 & 70.9 & 4.8 & 10 & 65 & 79 & 72.9 & 4.9 \\
\hline TBP & & 9 & 105 & 148 & 129.4 & 15.3 & 5 & 130 & 151 & 123.6 & 17.6 \\
\hline \multirow[t]{2}{*}{ TBD } & & 20 & 80 & 99 & 85.5 & 4.8 & 11 & 80 & 88 & 84.5 & 2.5 \\
\hline & & 57 & 66 & 77 & 70.6 & 3.8 & 9 & 68 & 76 & 72.2 & 2.8 \\
\hline \multirow[t]{2}{*}{ CGL } & & 6 & 172 & 181 & 175.5 & 3.9 & 2 & 175 & 178 & 176.5 & - \\
\hline & & 26 & 150 & 169 & 158.1 & 4.8 & 7 & 155 & 167 & 161.1 & 4.7 \\
\hline AGLl & & 44 & 74 & 96 & 83.4 & 5.1 & 27 & 77 & 94 & 82.1 & 4.6 \\
\hline ABD & & 56 & 46 & 65 & 53.9 & 5.0 & 25 & 47 & 60 & 52.3 & 3.9 \\
\hline $\mathrm{MtGL}$ & & 23 & 250 & 304 & 281.0 & 17.8 & 3 & 252 & 272 & 265.3 & 11.5 \\
\hline $\mathrm{MtBP}$ & & 35 & 55 & 73 & 61.9 & 5.6 & 8 & 53 & 70 & 60.0 & 6.0 \\
\hline $\mathrm{MtSD}$ & & 24 & 30 & 48 & 37.1 & 5.3 & 3 & 30 & 37 & 34.3 & 3.8 \\
\hline MtBD & & 26 & 60 & 81 & 71.9 & 7.0 & 6 & 66 & 78 & 69.8 & 4.7 \\
\hline PhIGL & & 50 & 61 & 86 & 72.9 & 4.6 & 43 & 69 & 88 & 78.7 & 5.6 \\
\hline PhIBP & & 42 & 32 & 46 & 38.3 & 3.2 & 43 & 33 & 45 & 38.0 & 3.2 \\
\hline PhIBD & & 31 & 29 & 42 & 35.4 & 3.0 & 46 & 29 & 45 & 36.7 & 3.5 \\
\hline PhIIGL & & 19 & 41 & 56 & 49.5 & 3.5 & 30 & 49 & 59 & 54.5 & 3.0 \\
\hline PhIIBP & & 11 & 36 & 48 & 41.0 & 3.7 & 23 & 34 & 41 & 38.1 & 2.1 \\
\hline PhIIBD & & 11 & 31 & 41 & 35.7 & 2.9 & 18 & 30 & 37 & 33.7 & 2.5 \\
\hline PhIIIDLS & & 20 & 70 & 102 & 86.6 & 8.6 & 7 & 76 & 105 & 90.4 & 9.3 \\
\hline
\end{tabular}

Table 3. Frequency distributions of bone measurements in points in periods A and B.

\begin{tabular}{|c|c|c|c|c|c|c|c|c|c|c|}
\hline Points & $0-9$ & $10-19$ & $20-29$ & $30-39$ & $40-49$ & $50-59$ & $60-69$ & $70-79$ & $80-89$ & $90-100$ \\
\hline $\begin{array}{c}\mathrm{f} \\
\%\end{array}$ & $\begin{array}{c}158 \\
18.0\end{array}$ & $\begin{array}{c}78 \\
8.9\end{array}$ & $\begin{array}{c}142 \\
16.2\end{array}$ & $\begin{array}{r}113 \\
12.9\end{array}$ & $\begin{array}{c}\text { Period A } \\
112 \\
12.8\end{array}$ & $\begin{array}{l}66 \\
7.5\end{array}$ & $\begin{array}{c}68 \\
7.8\end{array}$ & $\begin{array}{c}54 \\
6.2\end{array}$ & $\begin{array}{c}42 \\
4.8\end{array}$ & $\begin{array}{l}44 \\
5.0\end{array}$ \\
\hline $\begin{array}{c}\mathrm{f} \\
\%\end{array}$ & $\begin{array}{c}43 \\
10.4\end{array}$ & $\begin{array}{c}49 \\
11.8\end{array}$ & $\begin{array}{c}51 \\
12.3\end{array}$ & $\begin{array}{c}46 \\
11.1\end{array}$ & $\begin{array}{c}\text { Period B } \\
44 \\
10.6\end{array}$ & $\begin{array}{c}51 \\
12.3\end{array}$ & $\begin{array}{c}50 \\
12.1\end{array}$ & $\begin{array}{c}33 \\
8.0\end{array}$ & $\begin{array}{l}24 \\
5.8\end{array}$ & $\begin{array}{l}23 \\
5.6\end{array}$ \\
\hline
\end{tabular}

Table 4. Correlation between categories $(1,2,3)$ and periods (A, B) - all characteristics together.

\begin{tabular}{ccccc}
\hline Combination & $\mathrm{n}$ & $\hat{\mathrm{n}}$ & $\mathrm{n}-\hat{\mathrm{n}}$ & Significance \\
\hline A1 & 378 & 353.9 & +24.1 & $\mathrm{~ns}$ \\
A2 & 359 & 373.6 & -14.6 & $\mathrm{~ns}$ \\
A3 & 140 & 149.5 & -9.5 & $\mathrm{~ns}$ \\
B1 & 143 & 167.1 & -24.1 & $<0.05$ \\
B2 & 191 & 176.4 & +14.6 & $\mathrm{~ns}$ \\
B3 & 80 & 70.5 & +9.5 & $\mathrm{~ns}$ \\
\hline
\end{tabular}


Table 5. Correlation between categories $(1,2,3)$ and periods (A, B) - forelimb.

\begin{tabular}{crrrc}
\hline Combination & \multicolumn{1}{c}{$\mathrm{n}$} & \multicolumn{1}{c}{$\hat{\mathrm{n}}$} & $\mathrm{n}-\hat{\mathrm{n}}$ & Significance \\
\hline A1 & 104 & 98.0 & +6.0 & $\mathrm{~ns}$ \\
A2 & 108 & 106.4 & +1.6 & $\mathrm{~ns}$ \\
A3 & 46 & 53.6 & -7.6 & $\mathrm{~ns}$ \\
B1 & 24 & 30.0 & -6.0 & $\mathrm{~ns}$ \\
B2 & 31 & 32.6 & -1.6 & $\mathrm{~ns}$ \\
B3 & 24 & 16.4 & +7.6 & $\mathrm{~ns}$ \\
\hline
\end{tabular}

Table 6. Correlation between categories $(1,2,3)$ and periods (A, B) - hindlimb.

\begin{tabular}{crrrc}
\hline Combination & \multicolumn{1}{c}{$\mathrm{n}$} & \multicolumn{1}{c}{$\hat{\mathrm{n}}$} & $\mathrm{n}-\hat{\mathrm{n}}$ & Significance \\
\hline A1 & 162 & 166.3 & -4.3 & $\mathrm{~ns}$ \\
A2 & 112 & 114.1 & -2.1 & $\mathrm{~ns}$ \\
A3 & 54 & 47.6 & +6.4 & $\mathrm{~ns}$ \\
B1 & 58 & 53.7 & +4.3 & $\mathrm{~ns}$ \\
B2 & 39 & 36.9 & +2.1 & $\mathrm{~ns}$ \\
B3 & 9 & 15.4 & -6.1 & $\mathrm{~ns}$ \\
\hline
\end{tabular}

Table 7. Correlation between categories $(1,2,3)$ and periods (A, B) - stylopodium.

\begin{tabular}{crrcc}
\hline Combination & \multicolumn{1}{c}{$\mathrm{n}$} & \multicolumn{1}{c}{$\hat{\mathrm{n}}$} & $\mathrm{n}-\hat{\mathrm{n}}$ & Significance \\
\hline A1 & 6 & 8.4 & -2.4 & $\mathrm{~ns}$ \\
A2 & 25 & 22.2 & +2.8 & $\mathrm{~ns}$ \\
A3 & 21 & 21.4 & -0.4 & $\mathrm{~ns}$ \\
B1 & 5 & 2.6 & +2.4 & $\mathrm{~ns}$ \\
B2 & 4 & 6.8 & -2.8 & $\mathrm{~ns}$ \\
B3 & 7 & 6.6 & +0.4 & $\mathrm{~ns}$ \\
\hline
\end{tabular}

Table 8. Correlation between categories $(1,2,3)$ and periods (A, B) - zeugopodium.

\begin{tabular}{clccc}
\hline Combination & $\mathrm{n}$ & $\hat{\mathrm{n}}$ & $\mathrm{n}-\hat{\mathrm{n}}$ & Significance \\
\hline A1 & 57 & 53.3 & +3.7 & $\mathrm{~ns}$ \\
A2 & 58 & 58.7 & -0.7 & $\mathrm{~ns}$ \\
A3 & 31 & 34.0 & -3.0 & $\mathrm{~ns}$ \\
B1 & 12 & 15.7 & -3.7 & $\mathrm{~ns}$ \\
B2 & 18 & 17.3 & +0.7 & $\mathrm{~ns}$ \\
B3 & 13 & 10.0 & +3.0 & $\mathrm{~ns}$ \\
\hline
\end{tabular}

Table 9. Correlation between categories $(1,2,3)$ and periods (A, B) - metapodium.

\begin{tabular}{crrrc}
\hline Combination & \multicolumn{1}{c}{$\mathrm{n}$} & \multicolumn{1}{c}{$\hat{\mathrm{n}}$} & $\mathrm{n}-\hat{\mathrm{n}}$ & Significance \\
\hline A1 & 115 & 109.3 & +5.7 & $\mathrm{~ns}$ \\
A2 & 89 & 94.9 & -5.9 & $\mathrm{~ns}$ \\
A3 & 52 & 51.8 & +0.2 & $\mathrm{~ns}$ \\
B1 & 22 & 27.7 & -5.7 & $\mathrm{~ns}$ \\
B2 & 30 & 24.1 & +5.9 & $\mathrm{~ns}$ \\
B3 & 13 & 13.2 & -0.2 & $\mathrm{~ns}$ \\
\hline
\end{tabular}


Table 10. Correlation between categories $(1,2,3)$ and periods (A, B) - acropodium.

\begin{tabular}{crrcc}
\hline Combination & \multicolumn{1}{c}{$\mathrm{n}$} & \multicolumn{1}{c}{$\hat{\mathrm{n}}$} & $\mathrm{n}-\hat{\mathrm{n}}$ & Significance \\
\hline A1 & 60 & 51.4 & +8.6 & $\mathrm{~ns}$ \\
$\mathrm{~A} 2$ & 102 & 102.4 & -0.4 & $\mathrm{~ns}$ \\
$\mathrm{~A} 3$ & 21 & 29.2 & -8.2 & $\mathrm{~ns}$ \\
$\mathrm{~B} 1$ & 51 & 59.6 & -8.6 & $\mathrm{~ns}$ \\
$\mathrm{~B} 2$ & 119 & 118.6 & +0.4 & $\mathrm{~ns}$ \\
$\mathrm{~B} 3$ & 42 & 33.8 & +8.2 & $\mathrm{~ns}$ \\
\hline
\end{tabular}

Table 11. Correlation between categories $(1,2)$ and periods $(\mathrm{A}, \mathrm{B})$ - males.

\begin{tabular}{clccc}
\hline Combination & $\mathrm{n}$ & $\hat{\mathrm{n}}$ & $\mathrm{n}-\hat{\mathrm{n}}$ & Significance \\
\hline A1 & 40 & 40.0 & 0 & $\mathrm{~ns}$ \\
A2 & 49 & 49.0 & 0 & $\mathrm{~ns}$ \\
B1 & 18 & 18.0 & 0 & $\mathrm{~ns}$ \\
B2 & 22 & 22.0 & 0 & $\mathrm{~ns}$ \\
\hline
\end{tabular}

Table 12. Correlation between categories $(1,2)$ and periods $(\mathrm{A}, \mathrm{B})$ - females.

\begin{tabular}{crrrc}
\hline Combination & $\mathrm{n}$ & $\hat{\mathrm{n}}$ & $\mathrm{n}-\hat{\mathrm{n}}$ & Significance \\
\hline A1 & 173 & 172.3 & +0.7 & $\mathrm{~ns}$ \\
A2 & 104 & 104.7 & -0.7 & $\mathrm{~ns}$ \\
B1 & 31 & 31.7 & -0.7 & $\mathrm{~ns}$ \\
B2 & 20 & 19.3 & +0.7 & $\mathrm{~ns}$ \\
\hline
\end{tabular}

Table 13. Differences between number of bones of males and females in periods $\mathrm{A}$ and $\mathrm{B}$.

\begin{tabular}{cccccccc}
\hline Period & \multicolumn{2}{c}{ Males } & & \multicolumn{2}{c}{ Females } & Significance \\
\cline { 2 - 3 } & $\mathrm{n}$ & $\%$ & & $\mathrm{n}$ & $\%$ & \\
\hline $\mathrm{A}$ & 89 & 24.3 & & 366 & 75.7 & $<0.01$ \\
$\mathrm{~B}$ & 40 & 44.0 & & 51 & 56.0 & ns \\
\hline
\end{tabular}

comparisons were begun using statistical methods. The stochastic table shows that the distribution of all small, medium and large dimensions in the two periods under comparison, $\mathrm{A}$ and $\mathrm{B}$, is not random, and that there is a significant deficiency of small dimensions in period B (Table 4). Dimensions connected with the forelimbs have a non-random distribution (Table 5), while dimensions of the bones of the hind limbs are distributed randomly (Table 6). The dimensions of the stylopodium (Table 7), zeugopodium (Table 8) and metapodium (Table 9) have a distribution which accords with probability analysis. Only the distribution of dimensions of the acropodium is not random (Table 10). In the above analyses there was no statistically significant deficiency or surplus in any bone in the correlation table.

In order to test whether the tendency for the dimensions of the aurochs skeleton to increase in period B which had been found in the joint analysis was identical for both sexes, the correlation between periods and categories of dimensions was examined separately for males and females (Tables 11 and 12). It was found that there was a rare 
and complete compatibility between the empirical distributions and those which had theoretically been predicted. The number of bones of females in period $\mathrm{A}$ had been much greater than those of males. This difference was statistically significant. In period B the small difference was not statistically significant (Table 13).

\section{Geographical differentiation}

Preliminary comparisons of all 25 osteometric characteristics of aurochs from Poland, from the East, from the West and from the South were carried out on the basis of the arithmetic means. Mean values, calculated for each geographical group, were similar in respect of variability (from minimum to maximum) and were very high (Table 14). However, in a majority (17) of characteristics, the arithmetic means of dimensions of aurochs from the West were a little lower than for aurochs from the East, and also often lower than for aurochs from the remaining groups. The range of variability on the whole coincides in all the groups. A few characteristics could not be compared on the basis of arithmetic means because the number of dimensions used to calculate the means was too small. Both this consideration, and the observation that aurochs in the Western group had slightly smaller mean dimensions, let us to make the following comparisons. The dimensions were transposed into points and arranged in frequency ranks that were common for all the characteristics examined within the framework of each geographical group (Table 15). The distribution of points that was typical of aurochs from the West exhibited a clear skewness, with clustering in that part of the scale reserved for small values. There was similar clustering in the distributions of points obtained for aurochs from the North. Since these were the dimensions of bones from one female, this group was not included in further analyses. The dimensions calculated in points in the remaining geographical groups not arranged in such an obvious way, and it was therefore necessary to begin to evaluate their distributions by statistical methods.

The share of small, medium and large dimensions in particular geographical groups was examined by means of stochastic correlation. The significance of the differences between the empirical distribution and that theoretically predicted proved to be very high (Table 16). In the group of aurochs from the East there were significantly more large and medium dimensions, and significantly fewer small dimensions. In the group of aurochs from the West there was found to be a significant deficiency of large dimensions and a surplus of small ones. In the group of aurochs from the South there was a significant surplus of large dimensions. Only the aurochs from Poland had a distribution of dimensions that was compatible with probability theory.

A significant link was found between geographical groups and the categories of dimensions of forelimbs (Table 17). In the group of aurochs from the East, there was a significant surplus of medium measurements. In the group of aurochs from the West, there was a significant deficiency of large dimensions and a surplus of small dimensions. In the group of aurochs from the South, there was a significant surplus of 


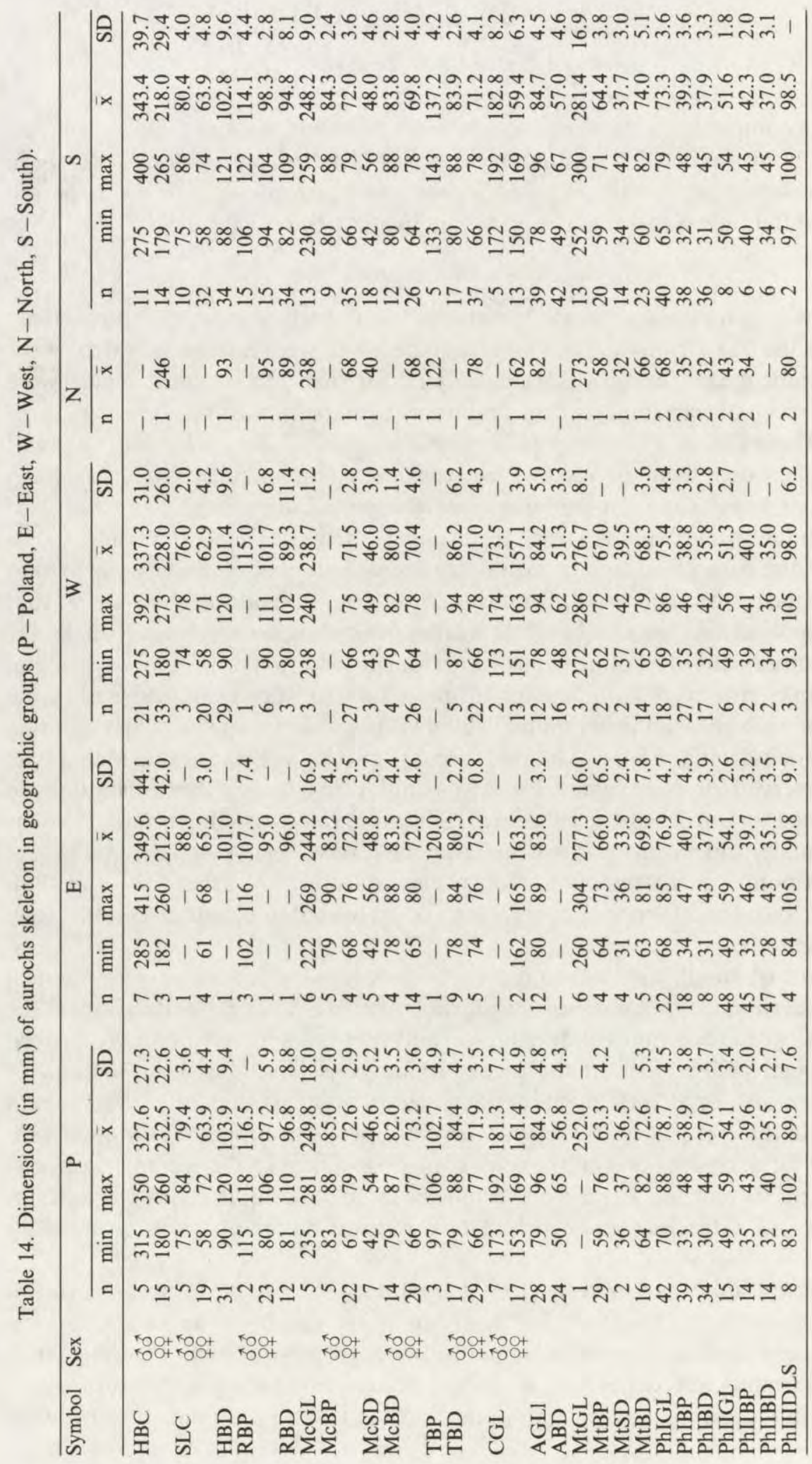


Table 15. Frequency distributions of bone measurements in points in geographic groups.

\begin{tabular}{|c|c|c|c|c|c|c|c|c|c|c|}
\hline Points & $0-9$ & $10-19$ & $20-29$ & $30-39$ & $40-49$ & $50-59$ & $60-69$ & $70-79$ & $80-89$ & $90-100$ \\
\hline \multicolumn{11}{|c|}{ Poland (P) } \\
\hline f & 42 & 48 & 78 & 78 & 82 & 44 & 59 & 34 & 27 & 26 \\
\hline$\%$ & 8.2 & 9.3 & 15.2 & 14.4 & $\begin{array}{c}16.0 \\
\text { Fast }(\mathrm{F})\end{array}$ & 8.6 & 11.5 & 6.6 & 5.2 & 5.0 \\
\hline$f$ & 17 & 17 & 27 & 42 & 35 & 44 & 39 & 40 & 21 & 16 \\
\hline$\%$ & 5.7 & 5.7 & 9.1 & 14.1 & $\begin{array}{c}11.7 \\
\text { West (W) }\end{array}$ & 14.8 & 13.0 & 13.4 & 7.0 & 5.4 \\
\hline $\mathrm{f}$ & 52 & 52 & 60 & 43 & 54 & 20 & 26 & 19 & 11 & 7 \\
\hline$\%$ & 15.1 & 15.1 & 17.4 & 12.5 & $\begin{array}{l}15.7 \\
\text { North (N) }\end{array}$ & 5.8 & 7.6 & 5.5 & 3.2 & 2.0 \\
\hline f & 10 & 4 & 6 & 6 & 1 & 1 & - & - & - & - \\
\hline$\%$ & 35.7 & 14.3 & 21.4 & 21.4 & $\begin{array}{c}3.6 \\
\text { South (S) }\end{array}$ & 3.6 & - & - & - & - \\
\hline f & 74 & 40 & 90 & 84 & 92 & 51 & 62 & 59 & 45 & 41 \\
\hline$\%$ & 11.6 & 6.3 & 14.1 & 13.2 & 14.4 & 8.0 & 9.7 & 9.2 & 7.0 & 6.4 \\
\hline
\end{tabular}

large dimensions and a deficiency of medium dimensions. In the group of aurochs from Poland, the distribution of small, medium and large dimensions was compatible with probability theory.

The distribution of dimensions of hindlimbs also exhibited a significant link between geographical groups and size categories (Table 18). It was only in the group of aurochs from the West that there was a significant deficiency of medium dimensions and a surplus of small dimensions.

In analysis of the dimensions of the stylopodium, it was necessary to exclude the group from the East because of insufficient data. In the remaining groups no difference was found in the distribution of small, medium and large dimensions (Table 19). In the dimensions of the zeugopodium the distribution of the three size categories was random (Table 20). Despite this, a significant surplus of medium dimensions was found in the group of aurochs from the East. The dimensions of the metapodium were unevenly distributed in particular geographical groups (Table 21). Among aurochs from the West, there was a significant deficiency of large dimensions and a surplus of small dimensions. In the group of aurochs from the South, a significant surplus of large

Table 16. Correlation between categories $(1,2,3)$ and geographic groups $(\mathrm{P}, \mathrm{E}, \mathrm{W}, \mathrm{S})$ - all characteristics together.

\begin{tabular}{crrrc}
\hline Combination & \multicolumn{1}{c}{$\mathrm{n}$} & \multicolumn{1}{c}{$\hat{\mathrm{n}}$} & $\mathrm{n}-\hat{\mathrm{n}}$ & Significance \\
\hline P1 & 168 & 171.0 & +3.0 & $\mathrm{~ns}$ \\
P2 & 259 & 243.8 & +15.2 & $\mathrm{~ns}$ \\
P3 & 87 & 98.2 & -11.2 & $\mathrm{~ns}$ \\
E1 & 61 & 99.2 & -38.2 & $<0.01$ \\
E2 & 160 & 141.4 & +18.6 & $<0.05$ \\
E3 & 77 & 57.4 & +19.6 & $<0.05$ \\
W1 & 164 & 114.5 & +49.5 & $<0.01$ \\
W2 & 143 & 163.2 & -20.2 & $<0.05$ \\
W3 & 37 & 66.3 & -29.3 & $<0.01$ \\
S1 & 204 & 212.3 & -8.3 & $\mathrm{~ns}$ \\
S2 & 289 & 302.6 & -13.6 & $\mathrm{~ns}$ \\
S3 & 145 & 123.1 & +21.9 & $<0.05$ \\
\hline
\end{tabular}


Table 17. Correlation between categories $(1,2,3)$ and geographic groups (P, E, W, S) - forelimb.

\begin{tabular}{ccccc}
\hline Combination & $\mathrm{n}$ & $\hat{\mathrm{n}}$ & $\mathrm{n}-\hat{\mathrm{n}}$ & Significance \\
\hline P1 & 48 & 50.6 & -2.6 & $\mathrm{~ns}$ \\
P2 & 62 & 56.9 & +5.1 & $\mathrm{~ns}$ \\
P3 & 24 & 27.5 & -3.5 & $\mathrm{~ns}$ \\
E1 & 15 & 18.1 & -3.1 & $\mathrm{~ns}$ \\
E2 & 30 & 20.1 & +9.9 & $<0.05$ \\
E3 & 3 & 9.8 & -6.9 & $\mathrm{~ns}$ \\
W1 & 52 & 37.3 & +14.7 & $<0.01$ \\
W2 & 39 & 41.4 & -2.4 & $\mathrm{~ns}$ \\
W3 & 8 & 20.3 & -12.3 & $<0.05$ \\
S1 & 71 & 80.0 & -9.0 & $\mathrm{~ns}$ \\
S2 & 75 & 88.6 & -13.6 & $<0.05$ \\
S3 & 66 & 43.4 & +22.6 & $<0.01$ \\
\hline
\end{tabular}

Table 18. Correlation between categories $(1,2,3)$ and geographic groups (P, E, W, S) - hindlimb.

\begin{tabular}{crrrc}
\hline Combination & $\mathrm{n}$ & $\hat{\mathrm{n}}$ & $\mathrm{n}-\hat{\mathrm{n}}$ & Significance \\
\hline P1 & 71 & 70.0 & +1.0 & $\mathrm{~ns}$ \\
P2 & 80 & 76.8 & +3.2 & $\mathrm{~ns}$ \\
P3 & 22 & 26.2 & -4.3 & $\mathrm{~ns}$ \\
E1 & 11 & 17.4 & -6.4 & $\mathrm{~ns}$ \\
E2 & 23 & 19.1 & +3.9 & $\mathrm{~ns}$ \\
E3 & 9 & 6.5 & +2.5 & $\mathrm{~ns}$ \\
W1 & 55 & 38.0 & +17.0 & $<0.01$ \\
W2 & 31 & 41.7 & -10.7 & $<0.05$ \\
W3 & 8 & 14.3 & -6.0 & $\mathrm{~ns}$ \\
S1 & 79 & 90.6 & -11.6 & $\mathrm{~ns}$ \\
S2 & 103 & 99.4 & +3.6 & $\mathrm{~ns}$ \\
S3 & 42 & 34.0 & +8.0 & $\mathrm{~ns}$ \\
\hline
\end{tabular}

Table 19. Correlation between categories $(1,2,3)$ and geographic groups (P, E, W, S) - stylopodium.

\begin{tabular}{crrrc}
\hline Combination & \multicolumn{1}{c}{$\mathrm{n}$} & \multicolumn{1}{c}{$\hat{\mathrm{n}}$} & $\mathrm{n}-\hat{\mathrm{n}}$ & Significance \\
\hline P1 & 13 & 13.5 & -0.5 & $\mathrm{~ns}$ \\
P2 & 14 & 12.8 & +1.2 & $\mathrm{~ns}$ \\
P3 & 5 & 5.7 & -0.7 & $\mathrm{~ns}$ \\
W1 & 14 & 12.2 & +1.8 & $\mathrm{~ns}$ \\
W2 & 10 & 11.6 & -1.6 & $\mathrm{~ns}$ \\
W3 & 5 & 5.2 & -0.2 & $\mathrm{~ns}$ \\
S1 & 13 & 14.3 & -1.3 & $\mathrm{~ns}$ \\
S2 & 14 & 13.6 & +0.4 & $\mathrm{~ns}$ \\
S3 & 7 & 6.1 & +0.9 & $\mathrm{~ns}$ \\
\hline
\end{tabular}

dimensions was found. Aurochs from Poland and from the East did not exhibit differentiation in the distribution of dimensions. In the acropodium, there was a statistically significant dependence between geographical groups and the category of dimensions (Table 22). In the group of aurochs from the East there was a surplus of large dimensions.

In order to check whether the results obtained on the differentiation of the size of the aurochs skeleton depending on geographical group did not result from a non-random accumulation of females in the West and males in the East and South, 
Table 20. Correlation between categories $(1,2,3)$ and geographic groups (P, E, W, S) - zeugopodium.

\begin{tabular}{crrcc}
\hline Combination & $\mathrm{n}$ & \multicolumn{1}{c}{$\hat{\mathrm{n}}$} & $\mathrm{n}-\hat{\mathrm{n}}$ & Significance \\
\hline P1 & 34 & 31.8 & +2.2 & $\mathrm{~ns}$ \\
P2 & 41 & 41.5 & -0.5 & $\mathrm{~ns}$ \\
P3 & 11 & 12.7 & -1.7 & $\mathrm{~ns}$ \\
E1 & 2 & 7.5 & -2.5 & $\mathrm{~ns}$ \\
E2 & 17 & 9.6 & +7.4 & $<0.01$ \\
E3 & 1 & 2.9 & -1.9 & $\mathrm{~ns}$ \\
W1 & 17 & 13.7 & +3.3 & $\mathrm{~ns}$ \\
W2 & 15 & 17.8 & -2.8 & $\mathrm{~ns}$ \\
W3 & 5 & 5.5 & -0.5 & $\mathrm{~ns}$ \\
S1 & 40 & 40.0 & 0 & $\mathrm{~ns}$ \\
S2 & 48 & 52.1 & -4.1 & $\mathrm{~ns}$ \\
S3 & 20 & 15.9 & +4.1 & $\mathrm{~ns}$ \\
\hline
\end{tabular}

Table 21. Correlation between categories $(1,2,3)$ and geographic groups $(\mathrm{P}, \mathrm{E}, \mathrm{W}, \mathrm{S})$ - metapodium.

\begin{tabular}{ccccc}
\hline Combination & $\mathrm{n}$ & $\hat{\mathrm{n}}$ & $\mathrm{n}-\hat{\mathrm{n}}$ & Significance \\
\hline P1 & 53 & 47.6 & +5.4 & $\mathrm{~ns}$ \\
P2 & 52 & 51.7 & +0.3 & $\mathrm{~ns}$ \\
P3 & 19 & 24.7 & -5.7 & $\mathrm{~ns}$ \\
E1 & 18 & 22.2 & -4.2 & $\mathrm{~ns}$ \\
E2 & 27 & 24.2 & +2.8 & $\mathrm{~ns}$ \\
E3 & 13 & 11.6 & +1.4 & $\mathrm{~ns}$ \\
W1 & 43 & 32.6 & +10.4 & $<0.05$ \\
W2 & 38 & 35.4 & +2.6 & $\mathrm{~ns}$ \\
W3 & 4 & 17.0 & -13.0 & $<0.01$ \\
S1 & 59 & 70.6 & -11.6 & $\mathrm{~ns}$ \\
S2 & 71 & 76.7 & -5.7 & $\mathrm{~ns}$ \\
S3 & 54 & 36.7 & +17.3 & $<0.01$ \\
\hline
\end{tabular}

Table 22. Correlation between categories $(1,2,3)$ and geographic groups $(\mathrm{P}, \mathrm{E}, \mathrm{W}, \mathrm{S})$ - acropodium.

\begin{tabular}{crrrc}
\hline Combination & \multicolumn{1}{c}{$\mathrm{n}$} & \multicolumn{1}{c}{$\hat{\mathrm{n}}$} & $\mathrm{n}-\hat{\mathrm{n}}$ & Significance \\
\hline P1 & 30 & 30.6 & -0.6 & $\mathrm{~ns}$ \\
P2 & 99 & 96.6 & +2.4 & $\mathrm{~ns}$ \\
P3 & 34 & 35.8 & -1.8 & $\mathrm{~ns}$ \\
E1 & 32 & 36.0 & -4.0 & $\mathrm{~ns}$ \\
E2 & 100 & 113.8 & -13.8 & $\mathrm{~ns}$ \\
E3 & 60 & 42.2 & +17.8 & $<0.01$ \\
W1 & 18 & 13.9 & +4.1 & $\mathrm{~ns}$ \\
W2 & 47 & 43.9 & +3.1 & $\mathrm{~ns}$ \\
W3 & 9 & 16.2 & -7.2 & $\mathrm{~ns}$ \\
S1 & 26 & 25.5 & +0.5 & $\mathrm{~ns}$ \\
S2 & 89 & 80.6 & +8.4 & $\mathrm{~ns}$ \\
S3 & 21 & 29.8 & -8.8 & $\mathrm{~ns}$ \\
\hline
\end{tabular}

the distribution of dimensions was compared separately for each sex. For males, the distribution was random (Table 23), but for females it was significantly differentiated (Table 24). A significant surplus of large dimensions was found for females from the East and a deficiency of these same dimensions for females from the West. A comparison of the number of bones of males and females in particular geographical groups shows that there were most females in the Western group, and then in the group 
Table 23. Correlation between categories $(1,2)$ and geographic groups $(\mathrm{P}, \mathrm{E}, \mathrm{W}, \mathrm{S})$ - males.

\begin{tabular}{cllcc}
\hline Combination & $\mathrm{n}$ & $\hat{\mathrm{n}}$ & $\mathrm{n}-\hat{\mathrm{n}}$ & Significance \\
\hline P1 & 23 & 24.8 & -1.8 & $\mathrm{~ns}$ \\
P2 & 30 & 28.2 & +1.8 & $\mathrm{~ns}$ \\
E1 & 17 & 13.0 & +4.0 & $\mathrm{~ns}$ \\
E2 & 11 & 15.0 & -4.0 & $\mathrm{~ns}$ \\
W1 & 23 & 18.6 & +4.4 & $\mathrm{~ns}$ \\
W2 & 17 & 21.4 & -4.4 & $\mathrm{~ns}$ \\
S1 & 33 & 39.6 & -6.6 & $\mathrm{~ns}$ \\
S2 & 52 & 45.4 & +6.6 & $\mathrm{~ns}$ \\
\hline
\end{tabular}

Table 24. Correlation between categories $(1,2)$ and geographic groups $(\mathrm{P}, \mathrm{E}, \mathrm{W}, \mathrm{S})$ - females.

\begin{tabular}{crrrc}
\hline Combination & $\mathrm{n}$ & $\hat{\mathrm{n}}$ & $\mathrm{n}-\hat{\mathrm{n}}$ & Significance \\
\hline P1 & 76 & 86.0 & -10.0 & $\mathrm{~ns}$ \\
P2 & 65 & 55.0 & +10.0 & $\mathrm{~ns}$ \\
E1 & 13 & 20.8 & -7.8 & $\mathrm{~ns}$ \\
E2 & 21 & 13.2 & +7.8 & $<0.05$ \\
W1 & 99 & 86.7 & +12.3 & $\mathrm{~ns}$ \\
W2 & 43 & 55.3 & -12.3 & $<0.05$ \\
S1 & 108 & 102.5 & +5.5 & $\mathrm{~ns}$ \\
S2 & 60 & 65.5 & -5.5 & $\mathrm{~ns}$ \\
\hline
\end{tabular}

Table 25. Differences between number of bones of males and females in geographic groups (P, E, W, S).

\begin{tabular}{lccrccc}
\hline Group & \multicolumn{2}{c}{ Males } & & \multicolumn{2}{c}{ Females } & \multirow{2}{*}{ Significance } \\
\cline { 2 - 3 } & $\mathrm{n}$ & $\%$ & & $\mathrm{n}$ & $\%$ & \\
\hline $\mathrm{P}$ & 53 & 27.3 & & 141 & 72.7 & $<0.01$ \\
$\mathrm{E}$ & 28 & 45.2 & & 34 & 54.8 & $\mathrm{~ns}$ \\
$\mathrm{~W}$ & 40 & 22.0 & & 142 & 78.0 & $<0.01$ \\
$\mathrm{~S}$ & 85 & 33.7 & & 167 & 66.3 & $<0.01$ \\
\hline
\end{tabular}

Table 26. Correlation between categories $(1,2,3)$ and geographic groups $(\mathrm{P}, \mathrm{E}, \mathrm{W}, \mathrm{S})$ - in period $\mathrm{B}$.

\begin{tabular}{crrcc}
\hline Combination & \multicolumn{1}{c}{$\mathrm{n}$} & \multicolumn{1}{c}{$\hat{\mathrm{n}}$} & $\mathrm{n}-\hat{\mathrm{n}}$ & Significance \\
\hline P1 & 92 & 103.2 & -11.2 & $\mathrm{~ns}$ \\
P2 & 141 & 140.8 & +0.2 & $\mathrm{~ns}$ \\
P3 & 65 & 54.0 & +11.0 & $<0.05$ \\
E1 & 2 & 7.3 & -5.3 & $\mathrm{~ns}$ \\
E2 & 13 & 9.9 & +3.1 & $\mathrm{~ns}$ \\
E3 & 6 & 3.8 & +2.2 & $\mathrm{~ns}$ \\
W1 & 29 & 15.6 & +14.4 & $<0.01$ \\
W2 & 15 & 21.2 & -6.2 & $\mathrm{~ns}$ \\
W3 & 1 & 8.2 & -7.2 & $<0.05$ \\
S1 & 28 & 24.9 & +3.1 & $\mathrm{~ns}$ \\
S2 & 37 & 34.1 & +2.9 & $\mathrm{~ns}$ \\
S3 & 7 & 13.0 & -6.0 & $\mathrm{~ns}$ \\
\hline
\end{tabular}

from Polish territories and in the South (Table 25). These differences were statistically significant. It was only in the East that the participation of bones of males was similar to that of female bones. 
In the previous section on the secular trend, it was found that in the later chronological group (B) the share of bones of males and females was balanced. Since this was the case, the geographical differentiation of aurochs bones was investigated for a second time, exclusively within this chronological group. The distribution of large, medium and small dimensions in Poland, in the East, in the West and in the South proved to be non-random (Table 26). A significant surplus of large dimensions was found in Poland, and a significant deficiency of these same dimensions in the West. In the West, there was also a surplus of small dimensions.

\section{Discussion}

The characteristics analysed because of their different positions in the skeleton, were not homogeneous, and could therefore exhibit various tendencies of change, both in size and in direction. For this reason, the result of comparisons of sizes of particular characteristics on the basis of the arithmetic means calculated for aurochs living in the Neolithic age, and then in the Bronze age and Iron age, was not surprising. Both the varied direction of these changes and their low value, together with the overlapping of the range of individual distribution, suggested an absence of clear changes over a period of about 7,000 years. Statistical analysis, however, showed that the overall size of the skeleton, examined on the basis of all the characteristics taken together, indicates that there was a tendency to increase in size with the passage of time. This was the opposite tendecy to that observed in other species, where was a reduction in size. The only large mammal in which an increase of dimensions has been attested is the badger (Degerbøl 1938).

A comparison of the size of the bones of both pairs of limbs showed that only the bones of the forelimbs exhibited a tendency to increase. A joint analysis of the dimensions of the forelimbs (without the metacarpus) does not show which dimensions influenced the significance of the difference obtained. Perhaps it was a small difference in a few dimensions that produced this effect. The lack of parallelism in the secular changes in the two pairs of limbs is often emphasised by researchers in the field of archaeozoology. The best example is the different results obtained for height of the withers in cattle if the dimensions of the metacarpus and metatarsus are taken as the basis for calculation. Coefficients calculated for contemporary cattle do not "fit" for prehistoric cattle, because the relationship between the lengths of the forelimbs and hind limbs has changed. Gautier and Rubberechts (1976), describing the bone remains from an early mediaeval settlement in Belgium, found that "in primitive breeds, the hindlegs are longer with respect to the forelegs than in advanced breeds". These observations obviously refer to the evolution of domestic cattle, but perhaps uneven changes over time of both pairs of limbs are a common characteristic of the whole species and not only for the domesticated form.

No clear secular changes have been noted in the successive segments of the two pairs of limbs: in the stylopodium, zeugopodium and metapodium. Only the most 
distal segment in relation to the axial skeleton (acropodium) exhibited a tendency to increase with the passage of time. For example, the mean length of the phalanges I increased by $8.0 \%$ of its value in the Neolithic age, and the length of the phalanges II by $10.1 \%$; the basic length of the phalanges III by $4.4 \%$.

It is difficult to explain why there was a tendency to increase in some elements of the aurochs skeleton. We tried to look for reasons in the uneven share of the bones of the two sexes in the two chronological groups compared. In the Neolithic, there were considerably more bones of females than of males in our material. The difference was so great that it cannot be explained by the random accumulation of females in the earlier period as a result of the more frequent hunting of females. There might have been more females than males because females were deliberately captured because it was perhaps easier to tame them and breed from them. However, in studies of the transitional forms between the aurochs and domestic cattle, in the same material of aurochs bones, considerably more metapodium of males than of females were distinguished (Lasota-Moskalewska and Kobryń 1989). This apparent contradicition results from the fact that in the study cited, sex was determined only on the basis of the metacarpal III + IV bones in the traditional way, in the field of correlation assigned by length and the index of width of the shank. However, in the present study, the bones of males and females were divided on the basis of frequency distribution of seven characteristics defined by particular dimensions. It was assumed that small dimensions applied to females and large dimensions to males. This division is only correct in broad outline. For it should be remembered that the group of small dimensions could contain transitional forms between the aurochs and domestic cattle, that is, aurochs being domesticated or freshly domesticated cattle. For example Bökönyi (1976), when he examined the Neolithic site at Anza in Yugoslavia stated clearly that "the freshly-domesticated individuals are small scale forms of the wild aurochs". This kind of interpretation of the small sizes of the characteristics examined would explain the uneven share of bones of males and "females". In the Neolithic period (A), when the process of domestication of the aurochs reached a height, the number of individuals that represented transitional forms must have been correspondingly large, and together with true females led to a preponderance of bones of "females". In the later period (B) the share of bones of males and females was balanced. This period covers the Bronze Age and Iron Age up to the early middle ages. In this period, the advanced nature of domestic cattle breeding (producing the next form - Bos taurus brachyceros and a considerable reduction in the size of the skeleton) meant that such mass-scale taming of aurochs was no longer necessary. It is therefore possible to assume that in the group of small dimensions the bones represent almost exclusively aurochs females. Taking the above discussion into account, it is possible that the observed increase in size of some dimensions of the aurochs skeleton with the passage of time may be only apparent.

Comparison of secular changes separately for the groups of males and females indicated a certain stabilisation in the size of seven osteometric characteristics of 
aurochs in the period from c. $5500 \mathrm{BC}$ to c. $1500 \mathrm{AD}$. Of course, we cannot be certain that other characteristics did not exhibit a tendency to secular changes. If however such a tendency did exist, it would consist in an increase in dimensions rather than a reduction. This tendency affected only a few elements of the skeleton and could have resulted from a disturbance of the composition of the Neolithic aurochs by transitional forms. For this reason we are inclined to believe that the size of the skeleton of aurochs in Central Europe - that is, in the zone in which they occurred longest - did not undergo change in the period of about 7,000 years from the Neolithic to the middle ages, that is, to the moment when the species became extinct. This view has been put forward by other researchers of aurochs bones, although their conclusions were based on a smaller quantity of data. Ekmann (1972), adducing Degerbøl and Fredskild (1970), writes that "the size of the urus has remained constant during postglacial times, while the teeth have become proportionally smaller". Jewell (1962) found also "Bos primigenius in Britain did not suffer any diminution in size in the post-glacial period and up to the time of its extinction". The study by Driesch and Boessneck (1976) also concludes that there was no change in the aurochs skeleton with the passage of time: "Funde des Ures aus kupfer- und frühbronzenzeitlichen Siedlungen Portugals lassen den neolithischen Uren Mitteleuropas aus gutten Biotopen entsprachen".

The geographical differentiation in the size of the aurochs is a separate question. This analysis was based on an even greater quantity of osteometric data, and covered a wider range both geographically and chronologically. This analysis shows that the overall size of the skeletons of aurochs occurring to the East of Poland was evidently greater than that of aurochs from Western Europe. Aurochs from areas lying to the South of Poland were also larger. Detailed comparisons showed that this trend applied to both pairs of limbs, but that it was more clearly discernible in the case of the forelimbs. It did not occur in the stylopodium or zeugopodium, but was more strongly stressed in the metapodium and acropodium.

It is difficult to draw conclusions from the results obtained, for we do not know why the distal segments of limbs are more greatly differentiated geographically that the segments which are situated closer to the axial skeleton. As was the case with investigation of the secular trend, we suspected that the geographical differentiation in the size of aurochs might have been only apparent and could have resulted from an unequal share of bones of males and females. It was only in the East that the share of bones of individuals of the two sexes was balanced. In the remaining groups there was a definite preponderance of bones of females. If the theory that females were more frequently hunted than males is correct, then it would be difficult to explain the fact that this was not practiced in the East, but only in the other regions. It is more probable to argue that the "females" were to a great extent transitional forms. In the East, where the domestication of cattle began earliest, transitional forms were considerably less frequent in the period under examination than was the case for example in the West. It should be stressed here that in the Eastern bone material from Iraq which is dated in the pre-ceramic Neolithic, transitional forms were excluded from the analysis. For this was 
material from our own research, classified according to more objective criteria laid down on the basis of our earlier work (Kobryn and Lasota-Moskalewska 1989, Lasota-Moskalewska and Kobryń 1989). It is possible to assume that in the East the aurochs bones really were the bones of aurochs and not those of transitional forms. This assumption seems to be confirmed by the result of the following analysis. For it was found that geographical differentiation in the size of aurochs did not occur among males, but was very strong among females. However, the fact that there was a significant surplus of bones of large females in the East reguires consideration. For in this group, if the bones of females were mixed with those of transitional forms, it was only to a minimal extent; in other words, in the East, the females were really large. The results of the next analysis provided a way out of the complications arising in interpreting these results.

Taking into account the fact that in the large period (the Bronze Age and the Iron Age) the share of bones of males and females was balanced, the geographical differentiation was examined for this period only. A clear difference was found, consisting in a considerable surplus of small aurochs in the West. This result is unequivocal, since it applies to a group which is not affected by participation of bones from transitional forms. We therefore take the view that geographical differentiation in the size of aurochs is a fact, consisting in a diminution of the dimensions of the skeleton from East to West. The aurochs from Poland occupy an intermediate position, which would indicate that these changes were continuous. Aurochs from the South seem to have been a little larger than those from Poland and the West, but this result is not so unequivocal as the East-West gradient.

Gedymin (1965), on the basis of examination of 22 skulls and several dozen dimensions of limb bones, claimed that early mediaeval aurochs from the Great Poland region and Kujavia (Poland) were very large, and were close in size to the upper limits of dimensions of aurochs from Denmark, Switzerland and Hungary. Skulls of aurochs from North-Eastern Poland examined by Ruprecht (1976), were larger still than the skulls presented by Gedymin. These observations show that the dimensions of various series of skeletons of aurochs from Poland were larger than the mean dimensions of skeletons from countries lying to the West of Poland, which is compatible with the gradient of reduction in size of aurochs from East to West that we have observed.

Vörös (1987) described the opposite direction of change, that is, a diminution in the size of the aurochs in the direction from North West to South East. His material covered aurochs from Hungary, and was compared, within the framework of the same sex, only with aurochs from Denmark and the Iberian Peninsula. These were Mesolithic materials. It is impossible to be certain whether in this period there were not already in Southern Europe transitional forms between the aurochs and domestic cattle. In the Northern territories, they certainly did not yet occur. In Southern Europe, because of the much warmer climate, an agricultural and stock breeding economy developed earlier, and therefore the aurochs could also have been tamed earlier. Perhaps, however, in the Mesolithic period, the geographical trend in the size of 
aurochs skeleton was different from that in the Neolithic and later periods.

The direction of change in the size of the aurochs that can be detected in our materials is compatible with the geographical gradient described for the deer and wild boar, as we have already pointed out in the introduction.

The reason for the existence of the geographical gradient is most readily sought in ecological differences. Both the aurochs and the two above mentioned species are connected with an environment of mixed forest. Forests of this kind were characteristic of large areas of Western Asia and of Eastern, Central and Western Europe. The limits of this zone are determined by latitude although longitude in this region does not form any clear boundaries. The reasons for the diminution in the size of the aurochs from East to West should therefore rather be narrowed down to climatic conditions (temperature and humidity). Vörös (1987), describing the contradictory nature of the directions of change in the size of aurochs and deer, suggested that for the aurochs the Atlantic climate (humid) must have been optimal, while for the deer the continental climate (dry) was optimal. Our research would seem to show that the two species preferred a similar type of climate.

It needs to be pointed out that females are more greatly subject to the gradient of diminution in size from East to West than males. It would seem that this could result from the more effective selection of males through sexual selection, in which males that were smaller or in worse condition had less chance of survival and their chances of taking part in reproduction were also less. However, the inheritance of somatic characteristics might be greater from the mother than from the father. Krasińska (1988) observed this phenomenon in the European bison; perhaps it also applies to other species of large mammals, especially those fairly closely related to the bison.

Wyrost and Chrzanowska (1985), investigating the secular trend to a diminution in dimensions of deer in Silesia (Poland), observed for example that it was more strongly present for females than males. Admittedly, these authors interpreted it as a result of non-random selection of archaeozoological material but it is possible that the material was random and that mechanisms of selection and inheritance were at work here.

Finally, it is worth emphasising that the phenomenon of a geographical gradient for the aurochs applies to mean, or in fact modal, values. In the populations living in each of the compared longitudes it was possible to find sporadically animals that were identically large and identically small. This indicates a high degree of individual variation and that the effect of the mechanisms described above was relatively discrete. It is for this reason that individual bones or small series cannot be used as a basis for evaluation of morphological differentiation of the species either in the geographical or chronological sense.

\section{References}

Beninde J. 1937. Zur Naturgeschichte des Rothirsch. Monogr. d. Wildsäugetiere 4: 1-223. 
Bökönyi S. 1976. The vertebrate fauna from Anza. [In: Neolithic Macedonia as reflected by excavation at Anza, Southeast Yugoslavia. M. Gimbutas, ed.]. Los Angeles, California: 313-374.

Calkin V. J. 1970. Drevniejšije domašnije životnyje Vostočnoj Evropy. Izdat. Nauka. Moskva: 1-279.

Degerbøl M. 1933. Danmarks Pathedyr i Fortiden i Sammenligning med recente Former. Vidensk. Medd. Dansk Naturhist. For. 96 (2): 74-96.

Degerbøl M. and Fredskild B. 1970. The urus (Bos primigenius Bojanus) and neolithic domesticated cattle (Bos taurus domesticus Linné) in Danmark. K. danske Vidensk. Selsk. biol. Skr. 17 (1): 1-177.

Driesch von den A. and Boessneck J. 1976. Zur Grosse des Ures, Bos primigenius Bojanus, 1827, auf der Iberischen Halbinsel. Säugetierkdl. Mitt. 40 (24): 66- 77.

Ekmann J. 1972. The urus female (Bos primigenius Bojanus) from Slägarp, Southern Sweden. Zool. Scripta 1: $203-205$.

Gautier A. and Rubberechts V. 1976. Animal remains of the Senecaberg Fortification (Grimbergen, Belgium, 12th century). Bul. d. Mus. Royaux d'Art et d. Hist. 48: 49-84.

Gedymin T. 1965. Tur (Bos primigenius Bojanus 1827) na ziemiach Wielkopolski i Kujaw. Rocz. Wyż. Szk. Roln. w Poznaniu 25: 21-37.

Góralski A. 1966. Kryterium $\Psi$ oceny istotności nadwyżki i niedoboru liczebności w elementarnej kostce wielodzielczej m-wymiarowej tablicy. Zesz. nauk. Polit. Warsz. 131, Mat, 7: 7-32.

Grigson C. 1969. The uses and limitation of differences in absolute size in the distinction between the bones of aurochs (Bos primigenius Bojanus) and domestic cattle (Bos taurus L.). [In: The domestication and exploitation of plants and animals. P. J. Ucko and G. W. Dimbleby, eds]. London: 227-294.

Jarman M. R. 1969. The prehistory of upper pleistocene and recent cattle, part I: East Mediterranean, with reference to North-West Europe. Proc. of the Prehist. Soc. 35 (11): 236-266.

Jewell P. 1962. Changes in size and type of cattle from Prehistoric to Mediaeval times in Britain. Ztschr. f. Tierzücht. u. Züchtungsbiol. 77: 159-167.

Jonsson L. 1986. From wild boar to domestic pig - a reassessment of neolithic swine of northwestern Europe. Striae 24: 125-129.

Kobryń H. and Lasota-Moskalewska A. 1989. Certain osteometric differences between the aurochs and domestic cattle. Acta theriol. 34: 67-82.

Krasińska M. 1988. Hybrydy żubra i bydła domowego. Zakł. Narod. im. Ossolińskich, Wyd. PAN, Wroclaw: $1-188$.

Kurtén B. 1965. The Carnivora of the Palestine caves. Acta zool. fen. 107: 1-74.

Lasota-Moskalewska A. 1980. The skeleton of a prehistoric cow with characteristics of both Primigenious and Brachycerous cattle. Ossa 7: 173-178.

Lasota-Moskalewska A. and Kobryń H. 1989. Description of intermediate forms in the evolution of Bos primigenius $f$. taurus on the basis of osteometric characteristics. Acta theriol. 34: 625-642.

Lasota-Moskalewska A., Kobryń H. and Świeżyński K. 1987. Changes in the size of the domestic and wild pig in the territory of Poland from the Neolithic to the Middle Ages. Acta theriol. 32: 51-81.

McDonald J. N. 1981. North American bison, their classification. Univ. California, Press, Berkeley: 1-316.

Morales A. 1979. A study of the size differences of red deer populations from Iberian Peninsula in prehistoric times. Proc. of the Third Intern. Archaeozool. Conf., Agricult. Acad., Szczecin 1: 607-616.

Muzzolini A. 1985. La variabilite de la taille chez l'aurochs Bos primigenius d'Europe et d'Afrique. Bul. Soc. Merid. Speleol. Prehist. 25: 23-36.

Mystkowska E. 1966. Morphological variability of the skull and body weight of the red deer. Acta theriol. 11: $129-194$.

Noddle B. 1982. The size of red deer in Britain - past and present with some reference to fallow deer. BAR, Intern. Series 146: 315-333.

Requate H. 1957. Zur Naturgeschichte des Ures (Bos primigenius Bojanus 1827) nach Schädel- und Skelettfunden in Schleswig-Holstein. Ztschr. f. Tierzücht. u. Züchtungsbiol. 70: 297-324. 
Ruprecht A. L. 1976. Ssaki czwartorzędu Białostocczyzny. Rocz. biał. 13: 261-282.

Vörös I. 1979. Archaeozoological investigations of subfossil red deer populations in Hungary. Proc. of the Third Intern. Archaeozool. Conf., Agricult. Acad. Szczecin 1: 637-642.

Vörös I. 1980. Zoological and palaeoconomical investigations on the archaeozoological material of the early Neolithic Körös Culture. Folia archaeol. 31: 35-64.

Vörös I. 1985. Early medieval aurochs (Bos primigenius Bojanus) and his extinction in Hungary. Folia archaeol. 36: 193-221.

Vörös I. 1987. An aurochs (Bos primigenius Bojanus) skeleton from the mesolithic peat-bogs at Kecel-Rózsaberek. Folia archaeol. 38: 65-88.

Wyrost P. and Chrzanowska W. 1985. Jeleń z terenu Śląska. [In: Dawna fauna Śląska w świetle badań archeozoologicznych.]. Prace Kom. Archeol., PAN Oddz. Wrocław, Wrocław 3: 103-152.

Received 19 July 1989, accepted 1 December 1989. 